\title{
Endoscopic submucosal dissection in the colorectum: Feasibility in the Canadian setting
}

\author{
Marietta lacucci MD PhD1, Gregory Eustace MD¹, Toshio Uraoka MD PhD², \\ Yutaka Saito MD PhD³ , Miriam Fort Gasia $\mathrm{MD}^{1}$, Jon Love $\mathrm{MD}^{1}$, Naohisa Yahagi MD PhD²
}

\begin{abstract}
M Iacucci, G Eustace, T Uraoka, et al. Endoscopic submucosal dissection in the colorectum: Feasibility in the Canadian setting. Can J Gastroenterol 2013;27(12):689-693.
\end{abstract}

Endoscopic submucosal dissection is a minimally invasive endoscopic technique for the removal of gastrointestinal tumours that is increasingly being used for colonic neoplasms to spare resection of colon in selected patients. Colonic endoscopic submucosal dissection is technically challenging and was initially pioneered in Japan but increasingly used in selected western centres. Its use in Canada is currently limited, and the authors review the challenges and opportunities, in addition to the unique training infrastructure required to practice the procedure under supervision. Specific tools are required to perform endoscopic submucosal dissection and meticulous attention to detail is essential. The authors provide a combined Japanese and Canadian perspective to this technique, and discuss training and performance of endoscopic submucosal dissection as well as potential indications.

Key Words: Colonic neoplasms; Colonoscopy; Endoscopic submucosal dissection; Endoscopic training

\section{WHAT IS ENDOSCOPIC SUBMUCOSAL DISSECTION?}

Endoscopic submucosal dissection (ESD) is a novel technique designed for the en bloc removal of early stage gastrointestinal tumours via minimally invasive endoscopic methods. Initially developed in Japan in the mid-1990s for gastric and esophageal lesions, its use has subsequently expanded to lesions in the colorectum, and is becoming increasingly accepted and used worldwide. In western countries, larger sessile colonic lesions are currently being removed using a 'raise and snare' technique known as endoscopic mucosal resection (EMR), while large and more difficult polyps are often referred for laparoscopic surgery despite many of them being benign tumours (1). Although it is the procedure of choice for sessile lesions in the west, EMR still presents many drawbacks. Due to piecemeal resection, it often does not provide accurate histological assessment and is associated with a high rate of local recurrence, which is then difficult to treat due to the local fibrosis from the initial EMR. For flat tumours, the more specialized ESD offers the benefits of resecting tumours en bloc, even with large lesions that progress to the submucosal layers, and provides more accurate histology and higher rates of cure (2-4). Indeed, studies by Hotta et al (5) and Saito et al (6) compared recurrence rates for large colorectal tumours removed using EMR and ESD. Tumours removed using traditional EMR showed a dramatically higher recurrence rate (23.5\%) compared with a recurrence rate of only $0.7 \%$ for those removed en bloc using ESD. Attempts are being made to expand its applications to both esophageal and colonic neoplasms, opening a wide number of indications for use for this novel and exciting technique. The present review provides an overview of the uses and challenges of ESD in colorectal neoplasms, and examines its feasibility and opportunities in the Canadian setting.

\author{
La faisabilité d'une dissection sous-muqueuse \\ endoscopique du colorectum dans le contexte \\ canadien
}

La dissection sous-muqueuse endoscopique, une technique endoscopique peu effractive pour faire l'exérèse de tumeurs gastrointestinales, est de plus en plus utilisée en présence de néoplasmes coliques, afin d'éviter la résection du côlon chez certains patients. La dissection sous-muqueuse endoscopique du côlon est difficile sur le plan technique. Elle a d'abord été utilisée au Japon, mais elle est de plus en plus courante dans certains centres occidentaux, même si elle demeure limitée au Canada. Les auteurs en examinent les difficultés et les avantages, en plus de l'infrastructure de formation unique nécessaire pour l'effectuer sous supervision. Des outils précis sont nécessaires pour procéder à une dissection sous-muqueuse endoscopique, et il est essentiel de faire preuve d'une rigueur méticuleuse. Les auteurs donnent un point de vue japonais et canadien combiné sur cette technique et traitent de la formation et de l'exécution de la dissection sous-muqueuse endoscopique ainsi que de ses indications potentielles.

\section{APPLICATION IN COLONIC NEOPLASMS}

The absolute indications for ESD in the colon are laterally spreading nongranular-type tumours $\geq 2 \mathrm{~cm}$ in size and laterally spreading granular-mixed type tumours $\geq 4 \mathrm{~cm}$ - lesions that cannot be resected in en-bloc fashion (7). Not surprisingly, indications for colorectal ESD and therapeutic applications have been developed mostly in Japan and are based around the Japanese Society of Gastroenterology classification system, which divides neoplasms based on morphology from sessile (stage 1) to laterally spreading (stage 4) (8). While firm criteria for ESD vary among centres, smaller lesions are generally treated with snare or endoscopic resection, while larger lesions with higher risks and superficial submucosal invasion are treated using a submucosal dissection. The National Cancer Centre of Japan approved ESD for laterally spreading tumours $>2 \mathrm{~cm}$ for nongranulating lesions and $>3 \mathrm{~cm}$ for granular type lesions $(8,9)$. In addition, ESD is used for large sessile lesions and any intramucosal tumours that do not lift with fluid injection. Other indications include lesions with biopsy-induced scars and sporadic circumscribed lesions in inflammatory bowel disease (IBD), in which en bloc resection technique is exceedingly difficult (Figure 1).

\section{APPLICATION IN DYSPLASIA/CARCINOMA IN IBD}

The appropriate management of intraepithelial neoplasia (IEN) in IBD is evolving with advances in endoscopic technology. Lesion resectability is now the most important characteristic influencing the decision to either continue endoscopic surveillance or recommend colectomy in patients with IBD. More recent studies suggest that these lesions are heterogeneous and not all subtypes may be strongly associated with progression to malignancy. Circumscribed raised lesions and

${ }^{1}$ Division of Gastroenterology $\mathcal{E}$ Hepatology, Endoscopy Unit University of Calgary, Calgary, Alberta; ${ }^{2}$ Division of Research and Development of Minor Invasive Treatment, Cancer Center, School of Medicine, Keio University; ${ }^{3}$ Endoscopy Division, National Cancer Center Hospital, Tokyo, Japan

Correspondence: Dr Marietta Iacucci, Division of Gastroenterology, Department of Medicine, University of Calgary, 2500 University Drive Northwest,

Calgary, Alberta T2N 1N4. Telephone 403-592-5015, fax 403-592-5090, e-mail miacucci@ucalgary.ca

Received for publication September 15, 2013. Accepted September 16, 2013 

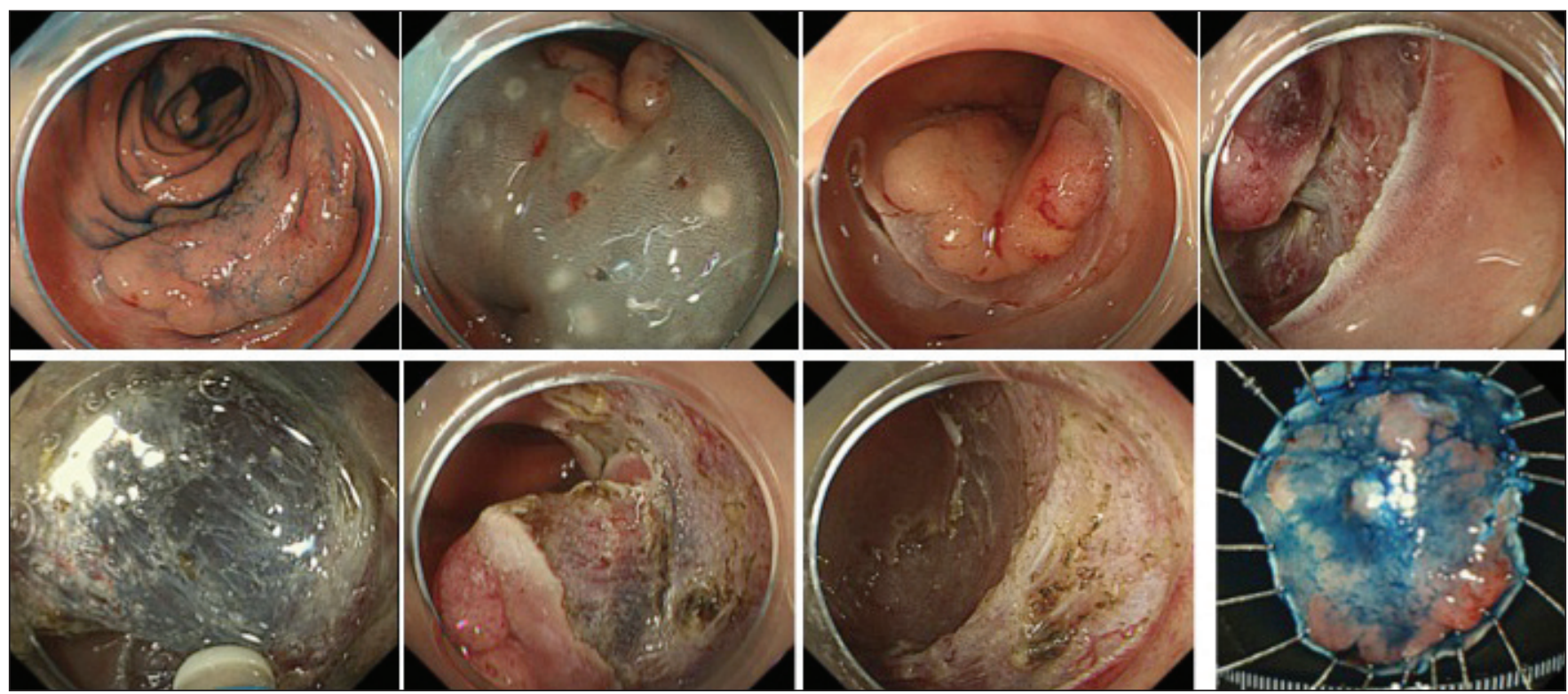

Figure 1) Large, laterally spreading nongranular-type tumour $>2 \mathrm{~cm}$

sporadic adenomas, with a sessile or pedunculated gross appearance, may be safely removed using polypectomy, despite occurring in patients with ulcerative colitis (UC). Polypectomy may be adequate treatment for adenoma-like dysplastic lesions in chronic UC $(10,11)$. Multiple studies have demonstrated that endoscopic surveillance is a safe and effective approach to the management of patients who have visible circumscribed neoplastic lesions resected during surveillance endoscopy. Hurlstone et al (12) evaluated 712 UC patients who underwent neoplasia surveillance with pancolonic chromoendoscopy and also had interval random biopsy specimens. One hundred thirtytwo circumscribed noninvase neoplasms were resected during index colonoscopy, including 46 raised lesions, 79 flat lesions and seven laterally spreading tumours, 18 of which harboured high-grade IEN. No subsequent colorectal cancer or flat IEN developed in any patients in this group throughout the study period. This underscores the importance of reconsidering colectomy as a treatment strategy in patients with flat IEN discovered in random biopsy specimens.

Indeed, in a study by Kisiel et al (13), the five-year cumulative incidence of cancer or flat dysplasia was $13 \%$, indicating that polypectomy may be safe for the management of adenomas occurring in most UC patients. Such patients should be able to avoid colectomy but obviously would need close monitoring.

Unfortunately, resection of an adenoma-like mass in chronic UC is often difficult because it is complicated by submucosal fibrosis and ESD may not be technically feasible. This barrier may be overcome using a combination technique. ESD-assisted EMR was performed in 69 patients with selected lesions associated with UC. The endoscopic resection of adenoma-like masses was technically feasible using the combination technique and was also curable. In fact, no metachronous circumscribed IENs or cancer was detected at median follow-up of 18 months. Overall cure rates for the ESD-assisted EMR cohort was $98 \%$ (14).

ESD may represent a future endoscopic therapeutic approach in circumscribed sporadic lesions in long-standing IBD to prevent unnecessary colectomies.

\section{COLONIC ESD - TECHNIQUES}

ESD has multiple technical challenges in the colon compared with the stomach, which relate to the anatomical features of the colon including its longer length, narrower lumen, extensive flexibility and thinner walls, longer procedure time and increased risk of perforation. Despite this, several novel techniques and technologies have been developed to aid in colonic ESD. Several keys factors are involved and are important in successful ESD. In a procedural review, Yahagi (15) reinforced the importance of appropriate bowel preparation to achieve optimal visualization. The manoeuvreability of the scope is also a very important key factor and the thinnest possible scope, often a gastroscope in the retroflex position if the lesion is rectal or proximal colon, should be used. A transparent hood or cap (Olympus, Japan) is then attached over the end of the scope, which enables tissue manipulation while maintaining visualization and lifting of the lesion and to help to control the knife during incision (Box 1).

\section{Tools required to perform ESD}

Electrosurgical knives: A number of specialized electrosurgical cutting knives have been developed for ESD including the Flex knife (KD-630L; Olympus), the Hook knife (KD-260R; Olympus, Japan) the Flush knife (DK2618JN; FUJIFILM, Japan), the B-Knife (Zeon Medical, Japan) and Mucosectom (Pentax, Japan).

While developed for ESD, these cuttings tools have some technical limitations. Despite the flex knife achieving excellent treatment results, the loop-shaped tip creates some issues, resulting in difficulty with knife length adjustments, frequent intraprocedure accumulation of debris on the tip and slippage of the knife tip away from the operating field. To remedy this, newly developed electrosurgical knives for colorectal ESD have been introduced since late 2010. These include Dual Knife (Olympus, Japan), Flush Knife including Ball-Tipped (BT) type (Fujinon Optical Co, Japan), B-Knife BT type (Zeon Medical, Japan), Mucosectom 2 (thin type) (Pentax, Japan), Safe Knife V (Fujunon, Japan), Clutch cutter (Fujinon, Japan) and SB knife (Sumitomo Bakelite, Japan) and IT Knife nano (Olympus, Japan).

The Yahagi Dual knife resembles a short needle knife with a small apical disk. It has a fixed knife length: $1.5 \mathrm{~mm}$ for esophageal and colorectal ESD and $2 \mathrm{~mm}$ for gastric ESD. The small disk is useful for marking and hemostasis in a closed position, and for stabilization of the knife movement against scarred or floppy tissue in an opened position, resulting in overall improved knife manoeuvreability and durability. Combining the endoscopist's knowledge and skill with the soft and flexible properties of the Flex and the Dual knives results in relatively safe and highly effective ESD outcomes. The Flush knife is another type of needle knife that has the added advantage of allowing local injection. A new Flush knife with a BT tip (Flush knife BT type; DK2618JB; FUJIFILM] [22]) has recently been developed to improve the hemostatic function of the standard model. In addition, the ball-tip reduces the procedure time in both upper and lower gastrointestinal ESDs compared with the standard Flush knife because it facilitates scooping $(16,17)$. 


\section{BOX 1
Performing colorectal endoscopic submucosal
dissection step by step}

The IT knife nano electrosurgical knife features has a shorter knife length for better manoeuvreability in narrow lumens. With a smaller insulated tip and a smaller electrode in the proximal end, the knife is well suited for use in organs with a thinner submucosal layer such as the colon. The IT knife nano enables rapid dissection and is safe.

Hemostatic forceps and hemoclips: Aside from cutting devices, specialized hemostatic forceps (Pentax and Olympus, Japan) and endoclips are necessary to stop intraprocedure bleeding and perforation that are common in ESD. Hemostatic forceps for ESD are different from hot biopsy forceps in that they have a pointed tip, enabling precise cauterization and preventing overcauterization that can lead to delayed perforation (15). In addition, endoclips are used in the eventual case of perforation, in which defects must be closed as quickly as possible to reduce the risk of peritonitis.

Carbon dioxide: Carbon dioxide $\left(\mathrm{CO}_{2}\right)$ insufflation is preferable for longer colonoscopic procedures during ESD because it can reduce patient pain and abdominal discomfort. Saito et al $(18,19)$ demonstrated that the use of $\mathrm{CO}_{2}$ insufflation reduced mean operation time as well as the need for sedation. Indeed, the mean $( \pm S D)$ dose of midazolam used during procedure was significantly lower in $\mathrm{CO}_{2}$-insufflated patients than the control group $(5.6 \pm 4.9 \mathrm{mg}$ and $9.7 \pm 5.9 \mathrm{mg}$, respectively; $\mathrm{P}=0.005$ ).

Injection solutions: Larger and difficult lesions require injecting a specialized hypertonic solution to provide a fluid cushion to protect the underlying tissues and permanently raise the lesion for resection. Hypertonic, long-term solutions that provide a sufficiently durable fluid cushion are needed for submucosal dissection.

Fluid choices vary, but have included hyaluronic acid, glycerol and normal saline $(20,21)$. A mixture consisting of a small amount of epinephrine $(0.001 \%)$ to control bleeding, indigo carmine dye $(0.004 \%)$, and a glycerol solution consisting of $10 \%$ glycerine, $5 \%$ fructose and $0.9 \%$ sodium chloride is the most popular solution used in Japan.

\section{Electrosurgical unit}

The electrosurgical generators from ERBE (ICC 200 and ICC 350, ERBE, Germany), which have endocut and multiple coagulation modes, are ideal for ESD. The addition of the VIO 300 D (ERBE, Germany) with new cutting and coagulation modes - 'dry cut' and 'swift coag' - can reduce bleeding during the ESD procedure (15).

\section{CHALLENGES AND TRAINING}

Training for ESD presents some future challenges that need to be addressed. To date, the majority of ESD training for western endoscopists has been performed in Japan at highly specialized centres. Several stepwise training protocols have been suggested to ensure competency before independent practice is permitted. Ohata et al (22) performed a retrospective study involving four trainees at NTT Medical Center in Tokyo, Japan, two of whom had extensive experience in gastric ESD (200 procedures) and two of whom had little experience ( 30 procedures). While the more experienced trainees had greater initial success, it took approximately 30 cases before the trainees' skills converged and reached an acceptable level of proficiency. A study by Hotta et al (23) examined the learning curve associated with colorectal ESD and suggested that at least 40 supervised procedures were needed to reduce
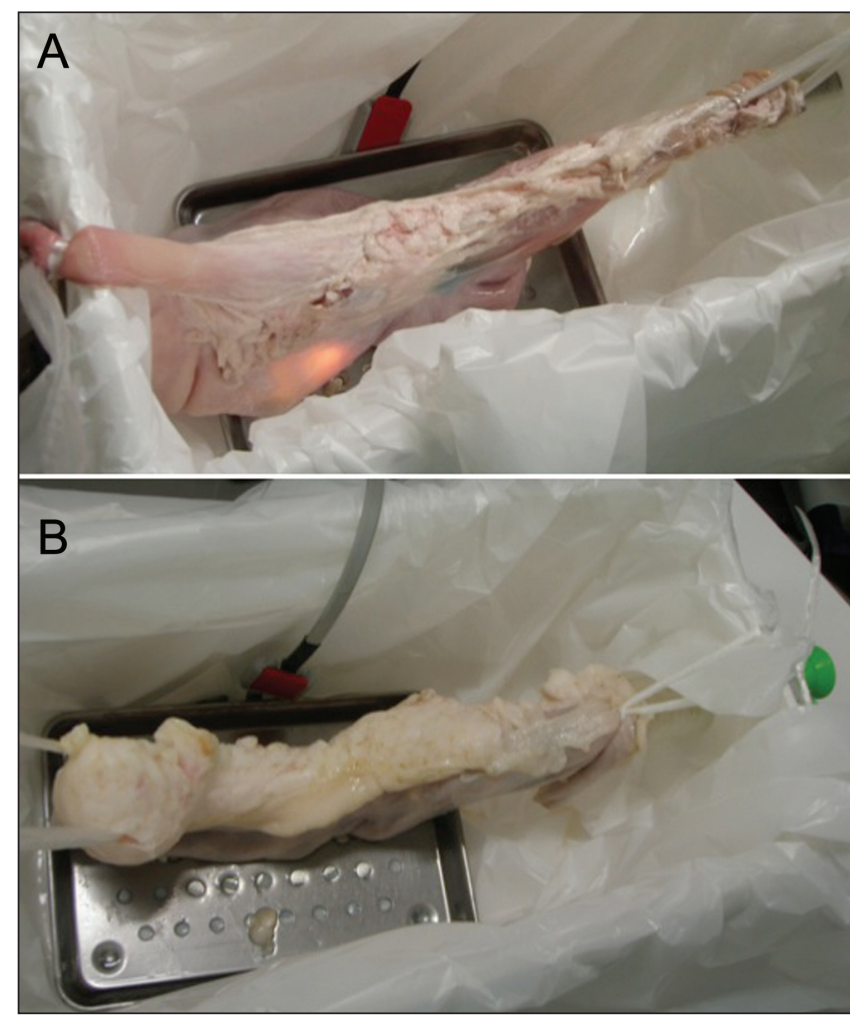

Figure 2) Isolated colonic endoscopic submucosal dissection (ESD) models. A Animal training model for gastric ESD. B Animal training model for colorectal ESD

risks of perforation to $<5 \%$, while 80 procedures were needed before an endoscopists was able to perform ESD in a timely manner with few complications. While the traditional model in Japan had been having trainees develop proficiency in gastric ESD before progressing to colorectal procedures, this model provides obvious barriers in a country such as Canada, where rates of gastric cancer are dramatically lower than in Japan, and where the opportunity to train under endoscopists experienced in ESD is more limited (24,25). A potential solution has been explored in European centres in the form of animal models. Berr et al (26) outlined a workshop for experienced endoscopists training in ESD. Anesthetized pigs were used to practice ESD techniques, with an overall perforation rate of $22 \%$. Of the endoscopists who progressed to perform human ESDs in their practice, the overall perforation rates were $9.7 \%$, suggesting an important role for initial training in animal models. In a study by Parra-Blanco et al (27), both live and dissected porcine models were used in ESD training. The authors found that the mean procedure time decreased by almost one-third comparing the first $50 \%$ of procedures performed with the latter $50 \%$, suggesting a strong learning curve and the importance of practicing in models in which patient safety is not in danger. Certainly, animal models would play an important role in any potential training for ESD in Canada. Animal training models have, to date, been either in vivo or ex vivo (live, or killed and dissected, respectively). While live models provide obvious benefits of most closely resembling a real clinical scenario, issues pertaining to animal welfare and transport/care of live animals would likely limit Canadian training programs to ex vivo models. Typical training systems use freshly processed porcine stomachs or large intestines that are used within hours of slaughter to preserve the elastic qualities of the tissue. Samples are washed and then fluid submerged to detect pre-existing mucosal defects. An overtube is attached to the top of the esophagus or the end of the sigmoid in gastric and colonic models, respectively, and the opposite end of the system is clamped to allow air insufflation. Models can then be used to demonstrate or practice ESD technique $(27,28)$ (Figure 2). While these models have drawbacks, including the inability to simulate active 
bleeding, they provide benefits such as safety and low cost $(29,30)$. Tanaka et al (31) also showed ex vivo training models to be effective in reducing perforation rates and procedure times. The prospect of practicing ESD in a country with little opportunity for expert supervision of real-life clinical procedures makes porcine models an attractive option in western countries such as Canada. It is, however, important that centres are set up with opportunities for simulation including pig-model ESD; this may require centres of excellence and the Canadian Association of Gastroenterology to come together to provide regional and national facilities.

\section{COMPLICATIONS OF ESD}

While ESD offers a less invasive solution to colonic neoplasms compared with surgery, it is not without complications. In a multicentre cohort study by Nakajima et al (32) in 2012, the authors compared outcomes and complications between EMR and ESD for colonic lesions $>20 \mathrm{~mm}$. From a total of 1845 procedures performed, perforation rates were increased to $1.6 \%$ in ESD compared with $0.8 \%$ in resections along with increased procedure times $(96 \mathrm{~min}$ ) compared with $18 \mathrm{~min}$. En bloc resection rates were dramatically better for ESD (94.5\%) compared with $56.9 \%$ for conventional endoscopic resection, with even higher discrepancies as lesions became larger.

In another large multicentre study by Saito et al (33), 1111 colorectal tumours treated using ESD from 1998 to 2008 were examined. The patients were from 10 specialized centres across Japan. Among the 1090 patients, total perforation rates were $4.9 \%$, while en bloc resection and curative resection rates were $88 \%$ and $89 \%$, respectively.

More recent studies conducted at the National Cancer Institute examining 806 colonic ESD procedures from 2004 to 2012 (34) showed an improved overall perforation risk of $2.8 \%$ and a delayed bleeding risk of $1.9 \%$, with a similar resection rate of $87 \%$ as reported

\section{REFERENCES}

1. Kudo S, Tamegai Y, Yamano H, Imai Y, Kogure E, Kashida H. Endoscopic mucosal resection of the colon: The Japanese technique. Gastrointest Endosc Clin N Am 2001;11:519-35.

2. Tajika M, Niwa Y, Bhatia V, et al. Comparison of endoscopic submucosal dissection and endoscopic mucosal resection for large colorectal tumors. Eur J Gastroenterol Hepatol 2011;23:1042-9.

3. Hotta K, Saito Y, Matsuda T, Shinohara T, Oyama T. Local recurrence and surveillance after endoscopic resection of large colorectal tumors. Dig Endosc 2010;22(Suppl 1):S63-8.

4. Nivatvongs S, Snover DC, Fang DT. Piecemeal snare excision of large sessile colon and rectal polyps: Is it adequate? Gastrointest Endosc 1984;30:18-20.

5. Hotta K, Fujii T, Saito Y, Matsuda T. Local recurrence after endoscopic resection of colorectal tumors. Int J Colorectal Dis 2009;24:225-30.

6. Saito Y, Sakamoto T, Fukunaga S, Nakajima T, Kiriyama S, Matsuda T. Endoscopic submucosal dissection (ESD) for colorectal tumors. Dig Endosc 2009;21(Suppl 1):S7-12.

7. Tanaka S, Terasaki M, Hayashi N, Oka S, Chayama K. Warning for unprincipled colorectal endoscopic submucosal dissection: Accurate diagnosis and reasonable treatment strategy. Dig Endosc 2013;25:107-16.

8. Saito Y, Otake Y, Sakamoto T, et al. Indications for and technical aspects of colorectal endoscopic submucosal dissection. Gut Liver 2013;7:263-9.

9. Fujishiro M, Yahagi N, Kakushima N, Kodashima S, Ichinose M, Omata M. Successful endoscopic en bloc resection of a large laterally spreading tumor in the rectosigmoid junction by endoscopic submucosal dissection. Gastrointest Endosc 2006;63:178-83.

10. Rubin PH, Friedman S, Harpaz N, et al. Colonoscopic polypectomy in chronic colitis: Conservative management after endoscopic resection of dysplastic polyps. Gastroenterology 1999;117:1295-300.

11. Pekow JR, Hetzel JT, Rothe JA, et al. Outcome after surveillance of low-grade and indefinite dysplasia in patients with ulcerative colitis. Inflamm Bowel Dis 2010;16:1352-6.

12. Hurlstone DP, Sanders DS, Atkinson R, et al. Endoscopic mucosal resection for flat neoplasia in chronic ulcerative colitis: Can we change the endoscopic management paradigm? Gut 2007;56:838-46. in the study by Saito et al (33). These decreasing perforation rates point to the importance of experience and, indeed, studies within Japan show higher complication rates in lower volume centres, while initial studies investigating ESD in Europe have reported slightly higher complication rates compared with more experienced endoscopists in Japan (35).

\section{OPPORTUNITIES FOR ESD IN CANADA}

Colorectal cancer screening programs are constantly expanding across Canada, thus exposing endoscopists to increasing numbers of large flat polyps encountered during colonoscopy. To date, these are generally resected in a piecemeal fashion or, occasionally, by EMR technique, both of which have been shown to increase the risk of recurrence and require frequent repeat colonoscopies to detect recurrent lesions. Some of these large lesions are referred to colorectal surgeons for resection, either transanally for low rectal lesions or by laparoscopic segmental colectomy. ESD represents a minimally invasive technique for complete resection of these lesions, with low complication rates and potentially at a lower cost than surgery.

Training programs and adequate clinical experience appear to be necessary to acquire a satisfactory and high level of skill for performing ESD. Before ESD can begin in Canada, collaborations with Japanese experts need to occur to improve the skills of Canadian endoscopists in this technique (36).

The second hurdle lies in funding. Colorectal ESD is not considered to be an advanced medical procedure that would be eligible for national health insurance coverage and the cost of this procedure has not yet been covered by the western national health insurance policies or by private payers. Further pharmacoeconomic studies need to be performed to determine the cost benefit of such an approach before Canadian patients can begin to benefit from this novel procedure.
13. Kisiel JB, Loftus EV Jr, Harmsen WS, Zinsmeister AR, Sandborn WJ Outcome of sporadic adenomas and adenoma-like dysplasia in patients with ulcerative colitis undergoing polypectomy. Inflamm Bowel Dis 2012;18:226-35.

14. Smith LA, Baraza W, Tiffin N, Cross SS, Hurlstone DP. Endoscopic resection of adenoma-like mass in chronic ulcerative colitis using a combined endoscopic mucosal resection and cap assisted submucosal dissection technique. Inflamm Bowel Dis 2008;14:1380-6.

15. Yahagi N. Endoscopic submucosal dissection in the colon. In: Waye JD, Rex DK, Williams CB, eds. Colonosocopy: Principles and Practice, 2nd edn. Malden: Blackwell Publishing; 2009:603-12.

16. Yahagi N, Uraoka T, Ida Y, et al. Endoscopic submucosal dissection using the flex and the dual knives. Techn Gastrointest Endosc 2011;13:74-8.

17. Toyonaga T, Man-I M, Fujita T, et al. The performance of a novel ball-tipped flush knife for endoscopic submucosal dissection: A case-control study. Aliment Pharmacol Ther 2010;32:908-15.

18. Saito Y, Otake Y, Sakamoto T, et al. Indications for and technical aspects of colorectal endoscopic submucosal dissection. Gut Liver 2013;7:263-9.

19. Saito Y, Uraoka T, Matsuda T, et al. A pilot study to assess the safety and efficacy of carbon dioxide insufflation during colorectal endoscopic submucosal dissection with the patient under conscious sedation. Gastrointest Endosc 2007;65:537-42.

20. Fujishiro M, Yahagi N, Kashimura K, et al. Different mixtures of sodium hyaluronate and their ability to create submucosal fluid cushions for endoscopic mucosal resection. Endoscopy 2004;36:584-9.

21. Uraoka T, Fujii T, Saito Y, et al. Effectiveness of glycerol as a submucosal injection for EMR. Gastrointest Endosc 2005;61:736-40.

22. Ohata K, Ito T, Chiba H, Tsuji Y, Matsuhashi N. Effective training system in colorectal endoscopic submucosal dissection. Dig Endosc 2012;24(Suppl 1):84-9.

23. Hotta K, Oyama T, Shinohara T, et al. Learning curve for endoscopic submucosal dissection of large colorectal tumors. Dig Endosc 2010;22:302-6.

24. Davis PA, Sano T. The difference in gastric cancer between Japan, USA and Europe: What are the facts? What are the suggestions? Crit Rev Oncol Hematol 2001;40:77-94. 
25. Uraoka T, Parra-Blanco A, Yahagi N. Colorectal endoscopic submucosal dissection: Is it suitable in western countries? J Gastroenterol Hepatol 2013;28:406-14.

26. Berr F, Ponchon T, Neureiter D, et al. Experimental endoscopic submucosal dissection training in a porcine model: Learning experience of skilled western endoscopists. Dig Endosc 2011;23:281-9.

27. Parra-Blanco A, Arnau MR, Nicolas-Perez D, et al. Endoscopic submucosal dissection training with pig models in a western country. World J Gastroenterol 2010;16:2895-900.

28. Bok GH, Cho JY. ESD hands-on course using ex vivo and in vivo models in south korea. Clin Endosc 2012;45:358-61.

29. Coman RM, Gotoda T, Draganov PV. Training in endoscopic submucosal dissection. World J Gastrointest Endosc 2013;5:369-78.

28. Vazquez-Sequeiros E, de Miquel DB, Olcina JR, et al. Training model for teaching endoscopic submucosal dissection of gastric tumors. Rev Esp Enferm Dig 2009;101:546-52.

30. Hon SS, Ng SS, Lee JF, Li JC, Lo AW. In vitro porcine training model for colonic endoscopic submucosal dissection: An inexpensive and safe way to acquire a complex endoscopic technique. Surg Endosc 2010;24:2439-43.
31. Tanaka S, Morita Y, Fujita T, et al. Ex vivo pig training model for esophageal endoscopic submucosal dissection (ESD) for endoscopists with experience in gastric ESD. Surg Endosc 2012;26:1579-86.

32. Nakajima T, Saito Y, Tanaka S, et al. Current status of endoscopic resection strategy for large, early colorectal neoplasia in Japan. Surg Endosc 2013;27:3262-70.

33. Saito Y, Uraoka T, Yamaguchi Y, et al. A prospective, multicenter study of 1111 colorectal endoscopic submucosal dissections (with video). Gastrointest Endosc 2010;72:1217-25.

34. Saito Y, Otake Y, Sakamoto T, et al. Indications for and technical aspects of colorectal endoscopic submucosal dissection. Gut Liver 2013;7:263-9.

35. Repici A, Hassan C, De Paula Pessoa D, et al. Efficacy and safety of endoscopic submucosal dissection for colorectal neoplasia: A systematic review. Endoscopy 2012;44:137-50.

36. Uraoka T, Parra-Blanco A, Yahagi N. Colorectal endoscopic submucosal dissection: Is it suitable in western countries? J Gastroenterol Hepatol 2013;28:406-14. 


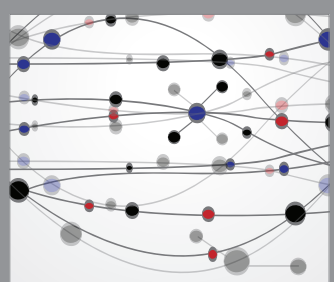

The Scientific World Journal
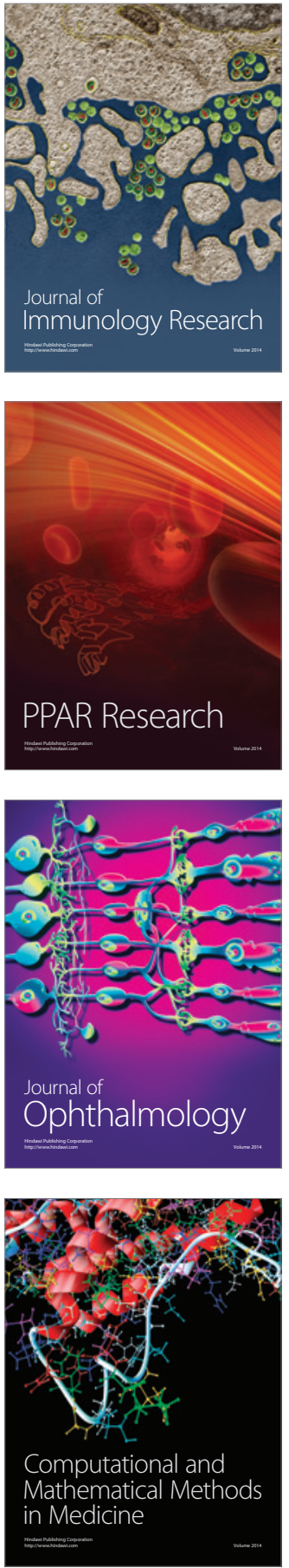

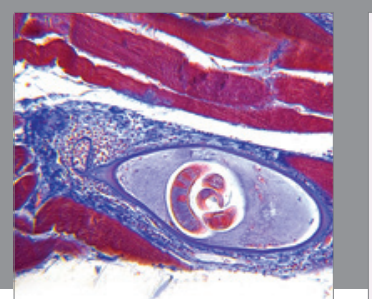

Gastroenterology Research and Practice

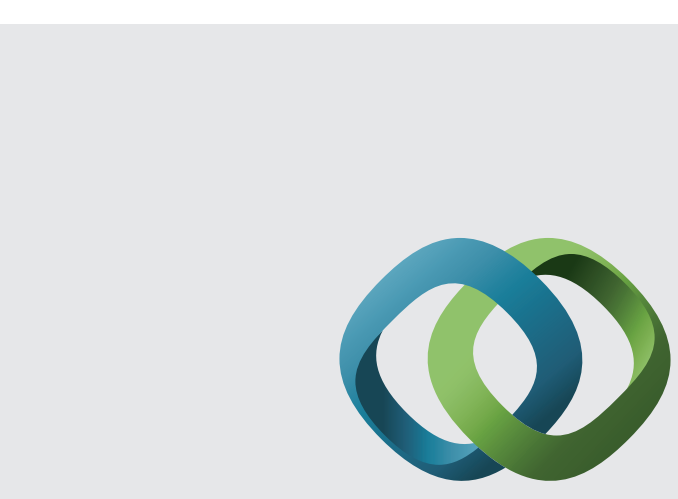

\section{Hindawi}

Submit your manuscripts at

http://www.hindawi.com
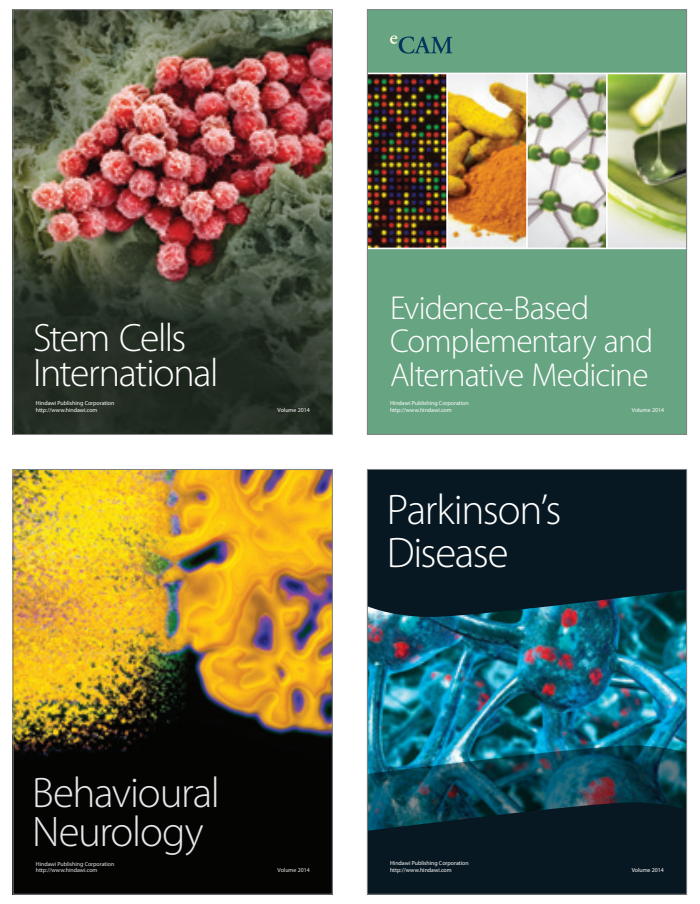
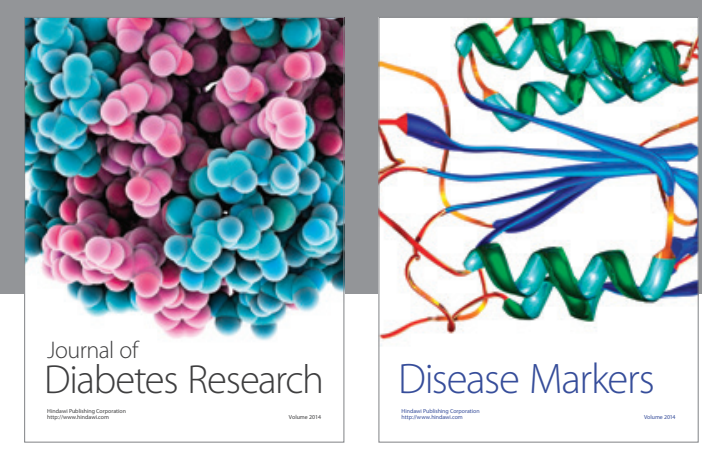

Disease Markers
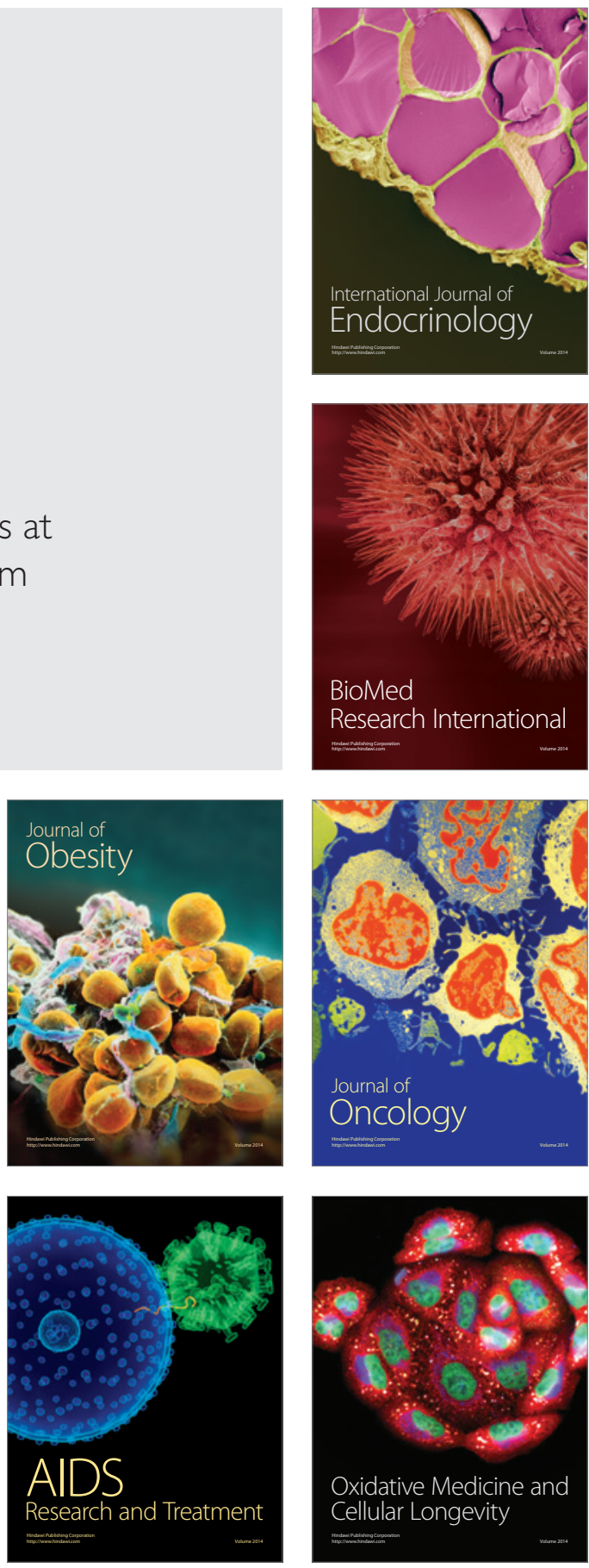